\title{
Introdução à crítica da razão desestatizante
}

Marcel Bursztyn

"Não sabemos para onde estamos indo. Só sabemos que a história nos trouxe até este ponto e [...] por quê. Contudo, uma coisa é clara. Se a humanidade quer ter um futuro reconhecível, não pode ser pelo prolongamento do passado ou do presente. Se tentarmos construir o terceiro milênio nessa base, vamos fracassar. E o preço do fracasso, ou seja, a alternativa para uma mudança da sociedade, é a escuridão”.

Eric Hobsbawm

O pensamento sobre a reforma do Estado deve imperativamente estar contextualizado em relação às particularidades de cada caso. A tendência de intelectuais (e políticos) a homogeneizar diagnósticos e prognósticos, como se vivêssemos em um mundo uno, tem levado a fabulosos equívocos de prescrição de remédios que tendem a agudizar problemas cujos sintomas são latentes.

Vivemos uma era de grandes mudanças nas estruturas públicas, produto de uma crise incontestável dos paradigmas que orientaram a estruturação dos Estados nacionais contemporâneos. Por razões diversas, que resultam de histórias também diversas, a crise do Estado é um fenômeno marcante nesse fin-de-siècle.

Hobsbawm (1995) avalia que o século XX (que para ele se iniciou com a Primeira Grande Guerra Mundial e terminou com o colapso da URSS) pode ser periodizado em três grandes momentos: a "catástrofe", marcada pelas grandes guerras, a crise de 1929 e o fascismo; os "anos dourados", das décadas de 50 e 60, caracterizados pela expansão econômica do

Doutor em desenvolvimento econômico e social e professor da Universidade de Brasília 
capitalismo e por profundas mudanças sociais; e o "desmoronamento" (de 1970 a 1991), quando ruem os sistemas institucionais que regulam o barbarismo contemporâneo, descortinando um futuro incerto, que resulta da brutalização da política e da irresponsabilidade teórica da ortodoxia econômica.

A década de 80 entrará para a história como um período de formidável transformação nas estruturas estatais, num sentido de reformas minimalistas. Em maior ou menor grau, os conceitos de "Estado Mínimo", "desestatização", "desregulação", "desregulamentação", "privatização", "downsizing", "mercado", "competitividade" e tantos outros, passaram ao lugar comum no vocabulário das decisões em matéria de políticas públicas. Não por acaso, todos os conceitos acima têm uma base etimológica de reversão de alguma tendência (“des...”) ou de inibição da natureza pública, no rumo de uma individualização (a ótica do $e u$, no lugar da do nós).

Sem dúvida, o mundo ingressou numa era de reversão da razão estatizante, que desde a queda do feudalismo se conformou como trajetória inexorável da evolução do mundo ocidental, ainda que com episódios de retrocesso. E, para se entender a razão desestatizante, é preciso primeiramente recordar a lógica que guiou a construção do Estado moderno. Isso ajudará a explicar, inclusive, que tal processo tem fundamento histórico, tanto em sua lógica construtiva quanto na fase atual de reformas. Em essência, a recorrência ao passado serve para mostrar que há casos bem distintos, que se caracterizam por diferenciais de escala, de tempo e de natureza.

\section{Genealogia da razão estatizante}

Entender a razão desestatizante requer um esforço retrospectivo que permita explicar "como" e "por que" os Estados modernos chegaram a tal ponto de intromissão na gestão da dimensão econômica das sociedades, com marcante atuação enquanto agentes produtivos, além das funções provedoras e reguladoras.

Panacéia salvacionista da década de 90 nos países menos desenvolvidos ou semi-industrializados do planeta, o discurso da desestatização apresentou-se como forte vetor de condução das políticas públicas nos anos 80, nos países mais ricos. Essa repetição de fórmulas que são transplantadas de uma realidade para outra, com alguma defasagem temporal, representa, na verdade, mais uma manifestação da tendência secular que marca de maneira determinante os Estados nacionais das antigas colônias ibéricas. Nascidos com resultado de uma lógica exógena, esses Estados tiveram a constituição de seus sistemas político-administrativos — bem como a própria formação de suas elites políticas e intelectuais - 
marcadamente orientadas pelas realidades metropolitanas. Desde o início, portanto, esta parte do mundo colonizado após as grandes navegações carece de fundamentos doutrinários endógenos.

Se, na Europa, o processo de expansão colonial, que resultou na incorporação do Novo Mundo à ordem econômica então constituída, foi respaldado por todo um aparato e obras científicas que serviam de fundamento e doutrina, o mesmo não se pode dizer das novas estruturas econômico-sociais que se produziram na América Latina. Criadas como apêndices políticos das respectivas metrópoles, as colônias estavam fadadas a cumprir o importante papel de fontes de extração de riquezas, alvo da doutrina mercantilista dos colonizadores. A formação de seus sistemas políticos se deu, nesse sentido, muito mais como um resultado de uma sucessão de eventos que obedeciam à lógica imediatista da pilhagem econômica, do que de estratégias previamente concebidas.

O resultado, em toda parte, foi o aparecimento de formas políticas e mesmo de modos de produção de riquezas, que representavam uma caricatura, deformada e extemporânea, de sistemas já experimentados e ultrapassados na Europa. O maior exemplo disso é, sem dúvida, a semelhança entre as estruturas do binômio latifúndio-minifúndio e as do feudalismo. Tal tipo de comparação, que ocupou boa parte do esforço reflexivo de intelectuais latino-americanos durante décadas, revela, por um lado, reais similitudes; mas reflete também um cacoete comum, que é o de se tentar decifrar os enigmas da realidade colonizada com fórmulas elaboradas para o mundo colonizador.

Evidentemente, não se trata de descartar o acervo teórico acumulado ao longo de séculos de pensamento político, mas é preciso que a recorrência a tais obras se dê com a devida contextualização, pois cada caso tem suas particularidades e idiossincrasias.

A busca da lógica, que levou à formação dos Estados modernos segundo moldes centralizadores, remonta à própria origem da ordem econômica correspondente. Na realidade, Estado e economia são duas instâncias diretamente associadas e interdeterminantes. Suas transformações resultam de relações de causa e efeito entre os mesmos, e a essência de tal processo evolutivo se situa na própria natureza dessa articulação: por um lado, a estrutura de poder político, materializada no aparelho de Estado, representa uma forma de exercício de uma autoridade externa a cada cidadão, sobre o conjunto da sociedade; por outro, essa estrutura, que se transforma segundo imperativos da evolução da economia, necessita dispor de sucessivos mecanismos que permitam seu reconhecimento enquanto autoridade.

Dois conceitos apresentam-se como úteis ao entendimento de tal questão: o de "autoritarismo" e o de "legitimidade". O primeiro, diz respeito às diferentes formas de exercício do poder, de encarnação da autoridade, 
externas a cada indivíduo. O segundo, está relacionado à capacidade de uma autoridade ser reconhecida enquanto tal. Ou seja, o primeiro depende do segundo.

A evolução de cada sociedade gera configurações específicas de Estados nacionais, que podem assumir formas variadas, segundo cada momento. Assim, na Europa feudal, o Estado se caracterizava por uma estrutura de poder central fraca, relativamente à autoridade dos senhores feudais. O Estado representava, ali, principalmente, a soma de sistemas locais de poder, que funcionavam quase que como nações autônomas. Mais do que o "rei", era o "senhor" que encarnava o poder, ao qual os "súditos" deviam obediência. O "soberano", enquanto poder, estava diluído nas autoridades de cada feudo. Os fundamentos da legitimidade desse Estado se encontravam nas esferas ideológica e moral: a obediência resultava das relações paternalistas e patriarcais, que eram asseguradas por rígidos condicionantes religiosos.

A decomposição do feudalismo implica mudanças radicais na forma dos Estados. A nova ordem do capitalismo comercial exigia estruturas de poder centralizadas, capazes de permitir a delimitação de fronteiras territoriais bem nítidas, onde deveria viger uma autoridade nacional. Os mecanismos que asseguravam a legitimidade ao feudalismo já não mais serviam. O "poder soberano" passa a carecer de normas jurídicas precisas, capazes de respaldar o monopólio da violência pelo Estado centralizador. Justiça e polícia tornam-se, então, elementos essenciais à nova forma de legitimação. Vale ressaltar que, no Estado absolutista, que corresponde a essa fase, o poder público se valia de uma estrutura burocrático-administrativa bem simplificada onde o Rei materializava o poder terreno da vontade divina, de forma absoluta (L'Etat c'est moi), bastavam dois ministérios: um para arrecadar (o das Finanças) e outro para assegurar a arrecadação (o da Justiça).

O Príncipe, de Maquiavel (1980), obra escrita em 1513, apresenta os fundamentos segundo os quais o Estado do capitalismo comercial deveria se estruturar. Só um Estado forte, centralizador, seria capaz de satisfazer as condições necessárias à expansão do capital. A força - a violência oficial — torna-se o paradigma maior da legitimidade do príncipe.

Ainda que a obra de Maquiavel tenha sido escrita com o intuito de orientar a Lorenzo di Medicis em sua busca de centralização do poder na Itália, seguindo o exemplo da Espanha e da França, sua influência foi muito além. Torna-se, de fato, uma obra fundadora do pensamento político renascentista, que evoluiria pari passu com a própria evolução dos sistemas econômicos. Assim, da mesma forma que autores como Hobbes (1971) servem de referência para o Absolutismo, outros autores posteriores vão 
surgir como arautos de uma nova era, a da Revolução Industrial, marcada por um Estado liberal, no sentido econômico e baseado em novas formas de legitimidade (o Estado Civil, de Rousseau).

A Revolução Francesa muda a fisionomia do Estado. Novas funções são agregadas a este, como conseqüências do Iluminismo, da industrialização e da necessária abertura de mercados em escala internacional. Já não bastavam apenas as antigas instituições responsáveis pela arrecadação e pela polícia/justiça. Como veremos mais adiante, novas pastas vão se somando paulatinamente ao aparelho de Estado.

O século XIX testemunha um incremento sistemático das estruturas públicas, ainda que dentro de uma ordem liberal. E o último quartil daquele século vai mostrar uma grande expansão dos aparelhos de Estado, sobretudo nas nações que dali em diante viriam a ingressar no rol de liderança do desenvolvimento em escala mundial. Pressionadas por imperativos de natureza social, as elites daqueles países foram agregando ao poder público novas responsabilidades, que sacudiram as estruturas de então, rompendo com práticas tradicionais típicas dos compromissos com os resquícios da velha ordem aristocrática feudal.

O caso da Alemanha de Bismarck é ilustrativo. Sua unificação, sob a hegemonia da Prússia, se deu mediante uma forte participação do Estado. Vencedor de três guerras, Bismarck pôde contar com uma inestimável entrada de capitais na Alemanha, que recebera grande indenização dos derrotados franceses. Com esses recursos, desenvolveu-se a indústria, mas também a especulação. Até que, em 1873, eclode uma grave crise econômica, típica de superprodução, superexploração e manipulação do mercado de ações (KENT,1978:88). A crise amplia o poder de fogo dos socialistas no flanco da política interna alemã. Paradoxalmente, Bismarck, que tanta glória obtivera em lutas externas, e que tanta reação manifestava contra o "perigo vermelho" que se expressava desde o levante operário de 1848, não conseguia impor seu liberalismo e anti-socialismo ao país. Industriais, agricultores e trabalhadores, todos, esperavam do Estado algum tipo de apoio (ibib.:98). E, nesse sentido, a história vê, com surpresa, o nascimento de uma forma política original e inovadora: o "liberalismo intervencionista de Estado".

É no governo conservador de Bismarck que as primeiras raízes do que viria depois a ser chamado de welfare state começa a se implantar. São adotadas leis de proteção ao trabalhador, em aspectos sobre doenças, acidentes, seguro por velhice, dentre outras. Ainda que discriminassem as mulheres e as crianças trabalhadoras, tais leis constituíram avanço para a época e serviram de referência para outros países (ver Quadro 1). 
Quadro 1: Introdução da seguridade social Países-membros da OCDE

\begin{tabular}{|lccccc|}
\hline & $\begin{array}{c}\text { Acidentes } \\
\text { industriais }\end{array}$ & Saúde & Pensão & Desemprego & $\begin{array}{c}\text { Alocação } \\
\text { familiar }\end{array}$ \\
\hline Bélgica & 1903 & 1894 & 1900 & 1920 & 1930 \\
\hline Holanda & 1901 & 1929 & 1913 & 1916 & 1940 \\
\hline França & 1898 & 1898 & 1895 & 1905 & 1932 \\
\hline Itália & 1989 & 1986 & 1898 & 1919 & 1936 \\
\hline Alemanha & 1971 & 1883 & 1889 & 1927 & 1954 \\
\hline Irlanda & 1897 & 1911 & 1908 & 1911 & 1944 \\
\hline Reino Unido & 1897 & 1911 & 1908 & 1911 & 1945 \\
\hline Dinamarca & 1898 & 1892 & 1891 & 1907 & 1952 \\
\hline Noruega & 1894 & 1909 & 1936 & 1906 & 1946 \\
\hline Suécia & 1901 & 1891 & 1913 & 1934 & 1947 \\
\hline Finlândia & 1895 & 1963 & 1937 & 1917 & 1948 \\
\hline Áustria & 1887 & 1888 & 1927 & 1920 & 1921 \\
\hline Suíça & 1881 & 1911 & 1946 & 1924 & 1952 \\
\hline Austrália & 1902 & 1945 & 1909 & 1945 & 1938 \\
\hline Nova Zelândia & 1900 & 1938 & 1898 & 1940 \\
\hline Canadá & 1930 & 1971 & 1927 & 1935 \\
\hline EUA & 1930 & - & 1935 & 1944 \\
\hline
\end{tabular}

Nota: Os dados incluem tanto os benefícios que inicialmente eram voluntários, mas contavam com a ajuda do Estado, quanto aqueles que eram compulsórios.

Fonte: Pierson (1991).

O final do século XIX foi também marcado pela adoção, nos países europeus e nos EUA e Japão, do princípio da universalização da educação, tarefa que dependia de uma maior participação do Estado e, paralelamente, implicava - como no caso francês - uma laicização do ensino. Já em 1850, os países escandinavos, a Alemanha, a Suíça, a Holanda, a Escócia e os EUA (os brancos) possuíam menos de $30 \%$ de sua população adulta em situação de analfabetismo. Em 1913, todo o grupo acima e mais a França, Inglaterra, Irlanda, Bélgica, Áustria, Austrália e Nova Zelândia, já se situavam num patamar de menos de $10 \%$ de adultos analfabetos [dados citados por Hobsbawm (1988:474)].

Tanto a educação quanto a saúde e a previdência social, ao se tornarem funções de Estado, implicavam um crescimento das estruturas públicas, em termos de participação do setor público no PIB e em termos 
de empregos públicos relativamente ao emprego total. E esse quadro segue uma tendência sempre crescente até que no ápice do Welfare State os números chegam a notáveis proporções, conforme se depreendem do Quadro 2.

Quadro 2: Papel do Welfare State na estrutura de emprego: Participação do setor público nos empregos em educação, saúde e serviços sociais (ESS) - 1985 (em \%)

\begin{tabular}{|l|c|c|c|}
\hline & $\begin{array}{c}\text { Emprego em ESS/ } \\
\text { Emprego total }\end{array}$ & $\begin{array}{c}\text { ESS Público/ } \\
\text { ESS Total }\end{array}$ & $\begin{array}{c}\text { ESS Público/ } \\
\text { Emprego Total }\end{array}$ \\
\hline Dinamarca & 28 & 90 & 25 \\
\hline Noruega & 22 & 92 & 20 \\
\hline Suécia & 26 & 92 & 25 \\
\hline Áustria & 10 & 61 & 6 \\
\hline França & 15 & 75 & 11 \\
\hline Alemanha & 11 & 58 & 71 \\
\hline Itália & 12 & 85 & 7 \\
\hline Canadá & 15 & 44 & 12 \\
\hline Reino Unido & 16 & 77 & 8 \\
\hline EUA & 17 & 45 & \\
\hline
\end{tabular}

Fonte: WEEP Data Files. In: Esping-Andersen (1990).

\section{O inevitável crescimento das estruturas estatais}

Até aqui vimos como o crescimento das funções do Estado, seja por desígnios da expansão da economia, seja por imperativos de natureza social, implica crescimento de suas dimensões político-administrativas. Vejamos agora, numa breve retrospectiva, alguns traços marcantes da evolução das configurações institucionais dos aparelhos de Estado, que obedecem a uma certa lógica ao longo do tempo. Em suma, busca-se mostrar que o lay-out institucional de cada Estado não é algo fortuito, mas sim resulta de processos históricos bem determinados. E, portanto, a reversão de desenhos está, necessariamente, associada à eliminação de funções, independentemente do atingimento pleno de seus objetivos.

Em seu estudo comparado sobre administrações e Estados, Gérard Timsit (1987:37-43) afirma, no que concerne ao número de elementos constitutivos de uma administração central, que "não existe, evidentemente, nenhuma solução nem evolução que sejam absolutamente comuns a todos 
os Estados". Entretanto, cada experiência, vista individualmente, pode representar um referencial importante, e o estudo de um conjunto de casos pode apontar um certo tipo de tendência geral, ao longo do tempo.

Historicamente, a maior parte dos Estados analisados por Timsit teve suas estruturas administrativas - em nível de gabinete ministerial - ampliadas ao longo do tempo, numa espécie de tradução institucional do princípio da divisão do trabalho. Assim, na França, as necessidades e a maior complexidade dos negócios impuseram um desdobramento da velha estrutura herdada do ancien régime (caracterizada por dois ministérios - Justiça e Finanças - e por quatro secretarias de competências geográficas). Com a Revolução de 1789, apareceram as pastas da Marinha, Guerra, Relações Exteriores, Interior, além daquelas duas préexistentes (a das Finanças foi transformada em Contribuições e Rendas Públicas). O número de ministérios cresce progressivamente, até que no último pós-guerra atinge — incluindo-se as secretarias de Estado - o patamar de 40 pastas.

Evolução similar ocorreu na Grã-Bretanha, que também respondeu aos imperativos da especialização ministerial. $\mathrm{O}$ gabinete, que contava com cinco membros em 1783, passa a uma dúzia nos anos de 1850; 17, no final do século e mais de 20 durante a Primeira Guerra Mundial. Atualmente, mesmo tendo passado pelo vendaval desestatizante de Margareth Thatcher, aquele país conta com um número em torno de 30 pastas.

$\mathrm{Na}$ Alemanha, e também seguindo a mesma tendência, existia, à época do Império Hohenzollern, um conjunto de cinco ministérios, que cobriam as funções clássicas dos Estados naquela época: Relações Exteriores, Guerra, Finanças, Interior e Justiça. Já na República de Weimar, o incremento das funções do Estado levaria à constituição de um gabinete com 10 membros. Durante o III Reich, contrariamente ao que se esperaria de um regime totalitário, a multiplicação de pastas levou a que se qualificasse o quadro institucional de "anarquia burocrática". Após a derrota de 1945 e a constituição da República Federal Alemã, mesmo o trauma institucional resultante do período nazista não impediu que o novo Estado já nascesse com 14 ministérios.

Mesmo no Brasil, cuja evolução administrativa foi marcada pela herança colonial - que inibia certas funções, como as Relações Exteriores — a tendência verificada ao longo da história pós-independência não foi muito diferente daqueles países europeus. À época do início da República, em 1889, o aparelho administrativo do Estado já contava com sete ministérios: Guerra, Marinha, Relações Exteriores, Justiça, Fazenda, Obras Públicas e Agricultura. Até o governo de Vargas, iniciado em 1930, esse quadro não muda muito. Mas a partir daí, surgem os ministérios do Trabalho, da Indústria e do Comércio, da Educação e da Saúde. Com a Segunda Guerra 
Mundial, cria-se o da Aeronáutica. Depois, outras três pastas são criadas, como resultado de desdobramentos e reestruturações. Em 1962, é criado o Ministério Extraordinário do Planejamento, que João Goulart entregou a Celso Furtado. Ao final do governo de José Sarney, o Brasil contava com 23 pastas em seu gabinete ministerial, depois de já ter tido 28 , no início do mandato previsto para Tancredo Neves. Collor varreu do organograma do Estado uma série de pastas, mas não suas funções, que foram agregadas num menor número de ministérios e de secretarias diretamente ligadas à Presidência da República. Passado o vendaval demolidor, a estrutura do Estado volta a ter um desenho muito parecido com o precedente.

O exemplo mais radical de autolimitação da administração pública é o da China, após a morte de Mao Tse-Tung: dos 98 ministérios e comissões ministeriais existentes em 1982, só restaram, depois de 1984, um total de 52 , o que significa uma redução de quase $50 \%$. Na época, o efetivo de funcionários foi reduzido em 200 mil, o que proporcionalmente à população do país não representou uma medida tão importante quanto a redução em 100 mil servidores britânicos, ${ }^{1}$ efetuada por Margareth Thatcher na primeira metade dos anos 80 , sem que houvesse, contudo, um reflexo profundo no nível do tamanho do gabinete.

Um elemento comum assinalado por Timsit em relação aos casos acima mencionados é o "modo de especialização das estruturas administrativas". Para o autor, dois mecanismos contribuem para o fenômeno. Em primeiro lugar, destaca-se o processo de "agregação" de instituições criadas a partir de peças que se juntam às estruturas já existentes, de forma a assegurar o desempenho de "novas funções" que até então não eram da alçada do Estado. É o caso, por exemplo, da pasta do Trabalho, que surge como corolário da ação regulamentadora do mercado e das relações trabalhistas. O segundo mecanismo que leva a uma especialização e complexidade do aparelho de Estado é a "diferenciação" das estruturas administrativas. Tal processo pode se dar pela própria evolução e aumento da complexidade de certos setores (caso da separação entre Viação e Obras Públicas no Brasil), ou como resultado de prioridade política (caso da Reforma Agrária).

Vale assinalar que a agregação de novas funções ao Estado pode se dar de duas maneiras: pela incorporação por parte do setor público de uma atividade que já existia anteriormente, mas não em escala universalizada, ou pelo aparecimento de uma nova preocupação social, que se torna objeto de políticas de regulação ou de regulamentações. No primeiro caso, cita-se o caso da educação, que existia de forma seletiva e privada, em grande medida assegurada pela Igreja, mas que ao se tornar universal e obrigatória passou a constituir um campo específico de atuação governamental. No segundo caso, o exemplo da proteção ao meio ambiente, 
que se torna preocupação pública nos últimos 25 anos, marcou o aparecimento de estruturas correspondentes em quase todos os países.

Entre a crescente especialização e a necessidade de coordenação eficiente, deve-se situar a busca de um tamanho "ótimo" de gabinete. Os países desenvolvidos parecem ter encontrado um certo equilíbrio quanto a esse número, pois nos últimos anos são relativamente pequenas as mudanças que empreenderam. Ainda que tenha havido uma redução de certas atividades (notadamente as ligadas à produção industrial), a estrutura do Estado não tem apresentado transformações substanciais naqueles países. E não poderia ser diferente, em se tratando de processo caracterizado por uma redivisão do trabalho entre os setores público e privado, mas não de uma eliminação de funções do Estado (esse ponto será retomado mais adiante).

Uma coisa, entretanto, é certa: o tamanho institucional dos aparelhos de Estado é o retrato do próprio espectro de atuação do setor público, enquanto promotor, formulador e executor de políticas públicas. $\mathrm{O}$ papel de regulação das sociedades foi evoluindo ao longo dos tempos, levando a tal configuração político-institucional.

O debate sobre eficiência, que tem servido de pano de fundo às teses de redução do tamanho do Estado, deve estar, portanto, condicionado a dois parâmetros bem claros e diferenciados: por um lado, a busca de um melhor desempenho, que envolve decisões e técnicas administrativas; e, por outro, a revisão do papel e das funções do poder público. Este último aspecto, que aparece nas pautas de discussão sobre reformas do Estado, não pode ser confundido com o primeiro. Ele deve, na verdade, ser avaliado à luz das particularidades de cada sociedade, do grau de pertinência e atualidade de cada uma das funções do poder público, das possibilidades e riscos de uma transferência de competências públicas a esferas privadas ou públicas não-estatais.

\section{A crise do Estado e seus muitos diagnósticos}

Uma das características desse fim de século tem sido a surpreendente convergência de análises quanto a certas evidências que se apresentam em nossas realidades políticas, econômicas e sociais. Talvez pelo fato de que a via socializante tenha entrado em colapso, ou porque o mundo vem mostrando problemas cujas soluções não são vislumbráveis com as fórmulas e instrumentos de que se dispõe, há um forte consenso quanto ao fato de que estamos diante de uma "crise de paradigmas" que expliquem e resolvam nossos impasses, mas se há consenso quanto aos fatos, não o há, por outro lado, quanto a um diagnóstico efetivo e, muito menos quanto ao modo de enfrentamento dos problemas. 
Particularmente, no tocante ao modelo de intervenção estatal constituído a partir do final do século passado, e que ganha vigor com a Revolução Russa de 1917 por um lado e com o New Deal norte-americano, por outro, muito se tem discutido nas academias e muito se tem feito na arena política. Um batalhão de intelectuais vem pontificando a respeito da crise do Estado, que chegou a impasses tanto pelo lado fiscal, quanto operacional.

A perda de legitimidade social do modo de intervenção estatista não deixa dúvidas. Entretanto, em cada sociedade particular, as razões e o tipo de manifestação dos problemas tendem a ser bem específicos. Há semelhanças e traços comuns, perceptíveis em toda parte. Assim, a dimensão fiscal tem se mostrado como um fator limitante, seja pelo lado da disponibilidade de recursos orçamentários que permitem a continuidade do modelo vigente, seja pelo fato de que o financiamento dos déficits resulta em incremento na carga tributária.

$\mathrm{Na}$ literatura internacional, o mote tem sido a crise do Welfare State, ou, como insistem os franceses, do Etat Providence. Evidentemente, trata-se, ali, da saturação de um modelo bem particular àquelas realidades.

Rosanvallon (1981) assinala que o que está em jogo hoje não é o tamanho ou o peso tributário da crise do Estado Providência. Para ele, a crise é bem mais profunda: ela reflete uma outra crise, que é a das relações entre Sociedade e Estado.

Mas por que esta crise se manifesta hoje?

O autor citado intui três possíveis explicações para esta indagação:

1) primeiramente, porque onde existe o Estado Providência (E-P) já cumpriu, mesmo que com falhas, seu papel de redução das desigualdades;

2) o crescimento já não mais representa o papel de "lubrificante" social (ou seja, a mecânica do E-P não está sendo acompanhada de reformulações no contrato social); e

3) atualmente, uma crítica de esquerda se junta à reação liberal tradicional.

As razões da crise do Welfare State (WS), conforme análise de Pierson (1991), podem ser sintetizadas nos seguintes pontos:

- mudanças na economia política internacional, acarretando erosão do compromisso entre o capital e o trabalho organizados;

- incompatibilidade, de longo prazo, com a economia de mercado;

- mudanças na estrutura de classes e nos padrões de consumo, gerando erosão da aliança entre as classes médias e trabalhadoras, pelo bem-estar público;

- erosão da solidariedade de classe no interior da própria "ampla" classe trabalhadora; e 
- incompatibilidade do WS baseado no crescimento, em termos de assegurar um genuíno bem-estar individual e social.

Um traço comum na análise dos dois autores é a constatação de que o Estado de bem-estar social, nos moldes como foi sendo edificado, perde sua capacidade de operar de forma socialmente satisfatória quando entra em colapso o mundo do trabalho. O pós-industrialismo e seu corolário - o desemprego - desmantelam os fundamentos da proteção social ao desequilibrar a relação securitária entre população ativa e inativa. O envelhecimento da sociedade, relativamente a uma cada vez menor taxa de natalidade, já vinha representando forte pressão sobre a população ativa, em termos de relação trabalhadores/aposentados. Com a crise do desemprego, outros mecanismos - como o seguro desemprego - se mostram também vulneráveis a tal ponto que perdem sua universalidade, passando a amparar apenas uma parcela cada vez menor da população. O surgimento do fenômeno da exclusão social no mundo desenvolvido - novidade desse fim de século — contribui, sem dúvida, para o questionamento do WS.

A mudança na composição dos custos do WS pode ser avaliada pelo Quadro 3, que mostra, para o caso francês, como vem aumentando a participação relativa dos gastos com "envelhecimento" da população e com o desemprego, ao mesmo tempo em que diminuem as rubricas doença e alocação familiar.

\section{Quadro 3: França - Distribuição percentual dos benefícios sociais}

\begin{tabular}{|lcc|}
\hline & $\mathbf{1 9 6 0}$ & $\mathbf{1 9 9 0}$ \\
\hline Velhice & $31 \%$ & $51 \%$ \\
\hline Doença & $33 \%$ & $26 \%$ \\
\hline Família & $31 \%$ & $13 \%$ \\
\hline Desemprego & $1 \%$ & $7 \%$ \\
\hline Outros & $4 \%$ & $3 \%$ \\
\hline
\end{tabular}

Fonte: Comptes de la Sécurité Sociale/França, apud. D’intignano (1993).

O diagnóstico da crise do WS pela corrente de pensamento da "nova direita" recorre ao pensamento de Hayek, Bucannan e outros autores, para reafirmar seus princípios antiestado. Pierson (1991:48-48) sumariza o clamor desse grupo de pensadores, em seis grandes pontos:

- o WS é antieconômico

- o WS é improdutivo

- o WS é ineficiente

- o WS é não-efetivo

- o WS é despótico 
Já a crise do Estado em países como o Brasil tem natureza bem diversa. Ainda que tenhamos seguido a fórmula do WS, promovendo legislações que regulamentavam o mercado e as relações de trabalho, que tenhamos instituído um sistema previdenciário e, até mesmo, mais recentemente, um seguro desemprego, nunca conseguimos universalizar sua abrangência. Uma ampla camada da população sempre esteve à margem de qualquer tipo de amparo público. Aliás, esse é um traço marcante de nossa sociedade desde a colônia. O grau de expectativa - e, portanto, de legitimidade - em relação ao Estado é aqui muito reduzido. A crise não se reveste, então, do mesmo caráter de desencanto como lá nos países do WS. Aqui, a crise é um misto de falta de políticas de bem-estar universalizadas, paralelamente a uma perda de efetividade dos poucos instrumentos de políticas sociais, junto às reduzidas parcelas da população que a elas tinham acesso. Ao contrário da saturação, do envelhecimento do WS, em nosso caso vivemos uma atrofia precoce de seu desenvolvimento.

Na verdade, o que está em crise, no caso brasileiro, é o Estado Patrimonial, cuja superação não se deu até o presente, mesmo que uma série de políticas trabalhistas tenham sido implantadas. A situação pode, em certa medida, ser comparada ao caso da Alemanha, à época de Weber: mesmo com os avanços em matéria de políticas sociais, promovidas no governo de Bismarck, aquele país ainda guardou por algum tempo fortes resquícios do patrimonialismo herdado de seu passado feudal. A velha nobreza sobrevivia, à sombra da máquina pública ampliada pelo crescimento das instituições do Estado. Daí, a assertiva weberiana de que os funcionários ("servidores") deveriam passar ao exercício da dominação das instituições públicas, em substituição aos notáveis (WEBER, 1971:221). Weber considerava, assim, que um corpo burocrático profissional e neutro deveria exercer efetivamente o poder legítimo de decidir sobre a condução dos negócios públicos, numa forma de dominação racional.

O fato de o Brasil ainda manter fortes traços da dominação tradicional (ibid::323-238) em suas estruturas políticas e institucionais o coloca em situação bem distinta dos países do WS, em termos de diagnóstico da crise do Estado.

Nesse sentido, ainda que haja sintomas parecidos, o diagnóstico não é o mesmo e, portanto, remédio (ou, pelo menos a dosagem) não pode ser o mesmo. 


\section{A razão desestatizante: a receita neoliberal e suas armadilhas}

Com a agudização da crise do sistema de WS (e não necessariamente do Estado nos países onde este se edificou), o terreno mostrou-se aparentemente fértil para reformas desestruturantes das instituições de proteção social. Entretanto, passados quase 20 anos desde o início das práticas desestatizantes, onde o modelo tory britânico serviu de referência, o que se viu foi muito mais privatização de empresas públicas do que eliminação da proteção social (ver Quadro 4). Aliás, a análise dos dados mostra que houve um incremento relativo da participação da Proteção Social na composição dos PIBs dos países mais desenvolvidos. Por exemplo, é verdade que o sistema de habitação popular do Reino Unido foi privatizado, mas o NHS (National Health Service) sobreviveu. Ainda que os serviços de catering e lavanderia dos hospitais públicos tenham sido objetos de franquias, o sistema não foi desmontado.

\section{Quadro 4: Proteção social em percentagem do PIB}

\begin{tabular}{|l|c|c|c|c|}
\hline & $\mathbf{1 9 6 0}$ & $\mathbf{1 9 7 0}$ & $\mathbf{1 9 8 0}$ & $\mathbf{1 9 9 0}$ \\
\hline EUA & 7,3 & 10,4 & 12 & 14,8 \\
\hline Japão & 4,1 & 5,7 & 10,5 & 11,5 \\
\hline CEE & - & - & 21,1 & $23^{*}$ \\
\hline Alemanha & 18,1 & 19,5 & 25,4 & $24^{*}$ \\
\hline Reino Unido & 10,2 & 13,2 & 16,4 & $20,3^{*}$ \\
\hline França & 13,4 & 16,7 & 23,5 & 26,6 \\
\hline Grécia & 7 & 9 & 11 & 20,6 \\
\hline Suécia & 10,8 & 16,7 & 32,4 & 33,9 \\
\hline
\end{tabular}

$*=1988-1989$

Fonte: OCDE, apud. D’intignano (1993:56)

Comentar as inúmeras armadilhas, mitos e falácias que revestem o debate sobre as fórmulas minimalistas de enfrentamento dos diferentes tipos de crise, que se manifestam atualmente nos diferentes tipos de Estados, é uma tarefa que extrapola os modestos limites deste texto. ${ }^{2}$ Alguns pontos, entretanto, merecem ser explicitados, enquanto elementos para reflexão que podem ajudar no enfrentamento dos desafios das reformas dos Estados.

O modo como o neoliberalismo vem pregando a hegemonia do mercado sobre o Estado, na regulação dos sistemas econômico-sociais, coloca-os em posição comparável a de revolucionários. Touraine (1994:145) chama a atenção para o fato de que "os liberais e os revolucionários têm em comum o fato de não pensarem em termos de agentes, mas em termos de racionalidade do sistema, quer seja uma questão de leis de mercado ou de socialismo científico". Para o autor, o Estado é sempre o agente central 
de mudança dos sistemas. Daí, "a ação revolucionária consiste em assumir o controle do Estado, a fim de dirigir esta mudança" (ibid.). Quanto a este aspecto, cabe assinalar que a "revolução neoliberal", ainda que na aparência se valha do desmantelamento de Estado, busca, na verdade, a conquista do mesmo, como forma de viabilizar a construção de um outro Estado: onde o mercado substitua as formas de mediação entre os diferentes atores sociais; onde o econômico substitua o social; onde a concorrência substitua a cooperação; onde o Eu substitua o Nós.

Uma confusão recorrente que vem se expressando no debate sobre a reforma do Estado é a da diferença entre "regulação" e "regulamentação", que não são a mesma coisa. O papel do Estado, independentemente do grau de interveniência direta enquanto ator econômico, é o de regular as relações entre os diferentes agentes do sistema econômico-social. Para regular, pode lançar mão de dois mecanismos: a regulamentação e a ação direta. Um não elimina o outro, mas a intensificação do uso dos dois, nas décadas precedentes, exacerbou o poder estatal e vulnerabilizou as instituições públicas.

No atual processo de reformas, as propostas minimalistas têm dado ênfase à simultaneidade da desregulação e da desregulamentação. Os riscos de tal conduta são graves. No caso das empresas públicas, por exemplo, que por seu caráter estatal já representam, em si, instrumentos de regulação, o Estado não necessita de muitas regulamentações; mas quando se pensa em privatizá-las, é preciso que sejam definidas regras de funcionamento, sobretudo quando se tratar de serviços públicos que passem a ser objeto de concessões à iniciativa privada.

Portanto, considerar a experiência do Reino Unido, as privatizações, que significaram redução de atividades governamentais (ainda que não tenha havido desestatização!), mostram que é preciso aumentar - e não reduzir - as regulamentações. Se estas se mostram obsoletas ou ineficientes, é o caso de revê-las, mas não de eliminá-las. Ou seja, melhor que o conceito de desregulamentação é a idéia de "re-regulamentação".

Propor medidas neoliberais simultaneamente ao enfraquecimento do Estado constitui um paradoxo. O neoliberalismo reifica as virtudes reguladoras da mão invisível do mercado. Exalta a competitividade, e exacerba assim a dimensão da individualidade, do Eu. Quando isso se dá num contexto de Estado fraco, a tendência é a barbárie descrita por Hobbes (1971:219), em que a inexistência da República ou Civitas (Leviatã) levaria à guerra de cada um contra seu vizinho. Anderson (1995), em seu Balanço do neoliberalismo assinala que para que este se implante, é preciso um Estado forte e não, como se supõe, fraco.

Crozier (1987:71) resume a crise do Estado numa fórmula simples: quanto maiores as necessidades e as demandas de intervenção, maiores 
as dificuldades de se intervir; quanto mais complexo o sistema de relações que gera o tecido social, maior o grau de mediação do Estado de que ele necessita. Daí, surge um paradoxo: quanto maior a liberdade dos participantes no jogo social, mais necessária se torna a organização. Nesse sentido, os apóstolos do neoliberalismo, que pregam o Estado-Mínimo, são incapazes de perceber uma regra fundamental: "é preciso muita organização para assegurar mais liberdade a um grupo crescente de pessoas".

Ao longo dos últimos 20 anos, muito se tem noticiado sobre o esforço dos países endividados do Terceiro Mundo em termos de equacionar seus débitos frente ao Sistema Financeiro Internacional. O Fundo Monetário Internacional — FMI, instituição que opera como verdadeira guardiã dos grandes bancos, desempenhou um importante papel enquanto força promotora ou indutora de reformas nas estruturas estatais dos países que buscavam renegociar suas dívidas externas. O receituário, sempre baseado em princípios de redução dos gastos do setor público, inclusive dos subsídios a atividades econômicas, segue um modelo generalizado, aplicável a qualquer país. A partir de tais condições, sucessivas cartas de intenção foram sendo produzidas pelos governos que buscavam adaptar-se às exigências impostas. Nesse jogo, parecia contar mais as intenções explicitadas do que as ações concretas, de tal modo que as referidas cartas de intenção se sucediam, sempre com promessas de difícil cumprimento, ainda que invariavelmente com incremento da austeridade na economia doméstica dos países. O laboratório neoliberal chileno apresentava-se como precursor de sucesso e paradigma.

Esse foi o "pano de fundo" de um traumático processo de desmantelamento institucional das estruturas estatais em vários países. $\mathrm{O}$ sucateamento das instituições era acompanhado também pelo sucateamento dos seus recursos humanos, de tal forma que operava-se um perverso ciclo vicioso, que invariavelmente remetia a uma perda de eficiência e de credibilidade no papel do Estado em cumprir certas funções. A missão providencial do poder público, em termos de identificar estratégias e promover o desenvolvimento, é substituída, no discurso tecnocrático, pelo mercado, entendendo-se este como um deus ex-machina. $\mathrm{O}$ "fetichismo do planejamento", como mão invisível que levaria à superação do atraso e da pobreza, foi sendo substituído pelo "fetichismo do mercado". Mas como o mercado, nos sistemas econômicos infantes, é uma abstração, sendo muitas vezes produto e dependente da própria ação estatal, é evidente que graves desajustes se produziram.

As privatizações de empresas públicas, que seguiam orientação tácita os receituários do FMI e do Banco Mundial, nem sempre correspondiam a um aumento da eficiência social, sobretudo aquelas relativas a serviços públicos. A busca de maiores resultados econômicos, no curto prazo, acabou levando a uma formidável negligência com o caráter público 
da prestação de certos serviços públicos. O caso argentino é rico em exemplos a esse respeito. Telefonia, energia e transportes urbanos, uma vez privatizados - e sem serem objetos de regulamentações que servissem de salvaguarda aos interesses públicos — passaram a orientar-se principalmente no rumo da rentabilidade ("qualidade e produtividade"), afastandose do princípio da universalização do atendimento. Assim, paralelamente ao surgimento do conceito de "cliente" como o objeto da busca de satisfação, ocorre também uma perversa redução no universo desses beneficiários: a exclusão de uma parte dos usuários — aqueles que não constituíam um mercado, no sentido econômico do termo - da categoria de clientes.

O caso argentino se presta, como bom exemplo, a uma avaliação da eficácia do processo de privatização, sob um ângulo estritamente econômico. Lá, o sistema de metrô e de serviços ferroviários metropolitanos, que em 1997 receberam subsídios do Estado da ordem de 270 milhões de dólares, deverão receber, em 1998, 318 milhões de dólares, o que corresponde a um incremento de $17,7 \%$. Se se considera que a privatização — no caso via concessão - se deu justamente por razões de ineficiência ou incapacidade do Estado em administrar tal serviço, parece um paradoxo que o próprio Estado deva arcar com crescentes subsídios a seus concessionários privados. E o paradoxo chegará a seu paroxismo no ano de 1999, quando está previsto o repasse de recursos públicos da ordem de um milhão de dólares diários, que igualam o valor da perda diária que representava a operação dos trens urbanos pelo Estado, em 1991, quando seu "alto custo" justificou a decisão pela privatização. ${ }^{3}$

$\mathrm{O}$ caso argentino é também eloqüente, para mostrar o quanto a fragilidade das estruturas de mercado, em contextos sociais caracterizados pela pobreza de amplas camadas da população, pode conduzir a situações de exclusão social. E evidencia, também, o papel universalizador do Estado, na extensão dos serviços públicos — e da cidadania — a todas as camadas da população, independentemente da rentabilidade global imediata de uma ou outra empresa prestadora de tais serviços. Mercado, produtividade e universalidade são conceitos que não podem ser reduzidos à simples análise econômica, em países menos desenvolvidos.

A esse respeito, o recente relatório do BIRD parece buscar redimir aquele organismo de suas práticas desestatizantes recentes ao reconhecer o papel determinante do Estado:

"...o Estado tem enorme responsabilidade no desenvolvimento econômico e social de um país e sobre a sustentabilidade do desenvolvimento. $\mathrm{O}$ potencial do Estado de alavancar, de promover e de mediar mudanças na busca de fins coletivos não tem limites. Onde tal capacidade foi bem utilizada, as economias floresceram. Mas onde isso não ocorreu, o desenvolvimento chocou-se contra um muro de tijolos." (BIRD, 1997:157). 
Aliás, conforme reconhece o próprio BIRD em seu relatório anual de 1994, o papel do setor público nos investimentos em infra-estrutura, por exemplo, é decisivo. Dados para a década de 80, justamente o período de pior desempenho dos Estados nas nações em desenvolvimento, indicam que o poder público foi o principal fator de geração de infra-estrutura, corroborando a tese de que em países pobres o mercado, em si, não atende a necessidades básicas cujos investimentos são de maior risco e retorno lento. Os investimentos totais em infra-estrutura, numa amostra de países, foram, naquele período, de $20 \%$ para nações de baixa-renda e de $22 \%$ para as de média-renda. Já os gastos estatais, no mesmo tipo de atividade, foram, respectivamente, de 38 e 58\% (BIRD,1994:14).

Mas se hoje o BIRD enfatiza o papel do Estado na promoção do desenvolvimento, não se pode dizer que isso sempre tenha se dado desta forma. Na realidade, tanto o BIRD como o FMI induziram, sobretudo nos anos 80 , práticas que se baseavam no diagnóstico de que grande parte da culpa pelo atraso e pela instabilidade da economia em desenvolvimento se devia à excessiva intervenção estatal. Em seus relatórios, estas instituições destacam o tema de que o Estado deve confiar mais no mercado como mecanismo de alocação e distribuição, deixando maior espaço ao setor privado (BABAL,1992:261). As políticas de ajuste estrutural, praticadas nos últimos 15 anos na América Latina, são o reflexo dessa doutrina.

O citado autor (ibid::262-263) identifica três grandes períodos na atuação dos organismos financeiros internacionais como o FMI e o BIRD. Na primeira fase que vai de 1946 a 1969, prevalecem políticas de empréstimos baseadas numa forte valorização dos princípios de mercado. $\mathrm{Na}$ segunda fase (décadas de 60 e 70), as operações se inclinam para o fortalecimento do papel do Estado nas economias em desenvolvimento, com notáveis reflexos sobre o crescimento das empresas estatais. O terceiro período, que se estende até recentemente, é marcado pelo desencanto com as políticas estatizantes, voltando-se a valorizar as virtudes do mercado.

O momento atual parece ser o de inflexão de tal tendência pelo reconhecimento de que também o mercado não resolve nossos graves problemas estruturais; talvez mesmo pelo fato de que o próprio mercado não está suficientemente estabelecido e amadurecido nesses países, carecendo de uma ação regulatória por parte dos Estados.

\section{Conclusão}

Uma das razões para a existência de tantos diagnósticos sobre a crise do Estado é o fato de que não se trata de um crise única, que possa ser generalizada. São muitas as crises que, embora simultâneas, revelam 
naturezas bem particulares em Estados bem particulares. Nossa época é, portanto, de "crises dos Estados", no plural. Assim, a busca de solução também não pode ser baseada em fórmulas universais, mas sim em diagnósticos de cada caso.

Isso não impede, evidentemente, que se recorra a experiências internacionais, para se buscar ensinamentos. Só que estes devem servir de referência, e não de norma.

O tema da reforma do Estado é, sem dúvida, um dos grandes desafios intelectuais e políticos desse fim de século. As práticas até aqui experimentadas vêm se mostrando limitadas, principalmente nos países menos desenvolvidos, onde o mercado tem mostrado fortes limitações em assumir o papel de regulador das forças sociais e econômicas, em sociedades tão complexas como as nossas, mas frágeis sob o ponto de vista político-institucional.

As análises e experiências têm sido carregadas de conteúdo voluntarioso, de natureza ideológica e casuísta. $\mathrm{O}$ resultado tem sido muito mais a demolição do Estado do que a edificação de uma via alternativa de organização societal, com todas as mazelas que isso implica.

A razão desestatizante mostra suas limitações, efetivamente, de forma tão peremptória, que até mesmo as instituições financeiras internacionais parecem estar recuando de sua radicalidade antiestatal.

O cenário, para essa virada de século, parece ser muito mais o de busca de um novo modo de atuação estatal do que a continuidade do seu desmantelamento. "Reestatização" seria um conceito mais adaptado, mas para tanto uma série de mudanças se torna necessária.

No caso brasileiro, considerando questões emergenciais que servem de "pano de fundo" para o debate da reforma do Estado, sugere-se alguns princípios como norteadores:

- Em primeiro lugar, aponta-se o imperativo de se implementar reformas de base, tão consensualmente necessárias, mas tão adiadas por vicissitudes do jogo político continuísta. Nesse contexto inserem-se a reforma agrária, a "despatrimonialização" do Estado, a universalização de fato da educação e das oportunidades sociais, o fim da exclusão social; enfim, a extensão da cidadania a toda a população.

- As regras do jogo devem ser claras e duradouras: não se pode mudar critérios ao belprazer de casuísmos dos dirigentes, que são transitórios e, com freqüência, obedecem muito mais à lógica patrimonialista e ao clientelismo político do que a critérios de competência técnica.

- O Estado é perene (ainda que, em sua evolução, passe por mudanças); os governos são temporários e têm a missão de gerir e assegurar o bom funcionamento do Estado. Nesse sentido, os governos têm o dever de melhorar a configuração do Estado e não têm o direito de desmantelá-lo. 
- Os servidores são funcionários do Estado e não de governos. A máxima de que o "chefe sempre tem razão" não pode se aplicar automaticamente ao serviço público. Os servidores devem ser uma salvaguarda do bom desempenho das instituições públicas.

- Quem deve ter estabilidade, em primeiro lugar, é o Estado e suas instituições; os servidores não podem colocar a sua estabilidade acima do bem comum.

- A estabilidade não pode ser apenas um direito: ela implica também em deveres. O Estado não pode se converter em um poder voltado prioritariamente para seus servidores: quem deve ser alvo das ações públicas, em geral, é o conjunto da população. Esta, sim, é o "cliente” do Estado. 
1 Vale ressaltar que essa redução não implica necessariamente demissões. O que houve, na realidade, foi uma transferência do nível de dependência funcional dos empregados das empresas que foram privatizadas, que deixaram de ser servidores públicos para se tornarem trabalhadores da iniciativa privada. É certo, contudo, que as privatizações britânicas acarretaram, num segundo momento, demissões em escala considerável.

2 A esse respeito, ver Bursztyn (1991a, 1991b).

3 Clarin, Buenos Aires, edições de 2/12/97 (p.22) e 3/12/97 (p.30). 
Anderson, Perry. "Balanço do neoliberalismo". In: SAder, Emir e Gentili, Pablo. (orgs.) Pós-neoliberalismo: as políticas sociais e o Estado democrático, Paz e Terra, RJ, 1995.

BABAI, Don. "El Banco Mundial y el FMI: apoyo o rechazo al papel del Estado?". In: VERNON, Raymond (org.). La promesa de la privatización: un desafio para la política exterior de los Estados Unidos. Fondo de Cultura Económica, Mexico, 1992.

BIRD, World development report 1994. Infrastructure for development. The World Bank/ Oxford University Press. Washington, 1994.

BIRD, World development report 1997. The State in a changing world. The World Bank/ Oxford University Press, Washington, 1997.

BurszTyn, Marcel. "Brasil: mitos e falácias da razão desestatizante". Textos para discussão, 8, Ciências humanas, Dept. Economia, UnB, 1991a.

Bursztyn, Marcel. "Regular o Estado". In: Raizes. ano X, v. 6, n. 8, p.49-68, Campina Grande, 1991b.

Crozier, Michel. Etat Modeste, Etat Moderne. Ed. Fayard, Paris, 1987.

D'intignano, Béatrice Majnoni. La protection sociale. Ed. De Fallois, Paris, 1993.

ESPING-ANDERSEn, Gosta. The three worlds of Welfare Capitalism. Princeton University Press, Princeton, 1990.

Habermas, Jürgen. Raison et Légitimité. Ed. Maspéro, Paris, 1985.

Hоввеs, Thomas. Léviathan. Ed. Sirey, Paris, 1971.

Hobsbawm, Eric. A Era dos Impérios - 1874-1914. Paz e Terra, RJ, 1988.

Hobsbawm, Eric. A Era dos Extremos: O breve século XX, 1914-1991. Paz e Terra, RJ, 1995.

Kent, George O. Bismarck e seu tempo. Ed. UnB, Brasília, 1978.

PIERSON, Christopher. Beyond the Welfare State, The Pennsylvania State University Press, PA, USA, 1991.

Rosanvallon, Pierre. La Crise de L'Etat Providence. Ed. du Seuil, Paris, 1981.

Timsit, Gérard. Administrations et Etats: étude comparé. PUF, Paris, 1987.

Touraine, Alain. "A idéia de revolução". In: Featherstone, Mike (org.). Cultura global: nacionalismo, globalização e modernidade. Vozes, Petrópolis, 1994.

Weber, Max. Economia y sociedad. Fondo de Cultura Económica, México, 1971. 


\section{Introdução à crítica da razão desestatizante Marcel Bursztyn}

O artigo compreende uma visão crítica sobre os processos de reestruturação do Estado baseados na lógica neoliberal, que caracterizam as reformas minimalistas da década de 80

O tema da reforma do Estado é visto como um dos grandes desafios intelectuais e políticos deste fim de século, devendo necessariamente ser contextualizado historicamente, uma vez que não existe uma única crise do Estado, mas várias crises dos Estados específicas e particulares, cujas soluções não são únicas nem universais, mas dependentes do diagnóstico de cada caso.

Entende-se que a razão desestatizante apresenta limitações, reconhecidas até mesmo pelas instituições financeiras internacionais que antes a defendiam. O cenário de um novo modo de atuação estatal é apresentado como mais provável, sendo o conceito de reestatização mais adequado para as mudanças que se fazem necessárias.

\section{Introdución a la crítica da la razón desestatizante \\ Marcel Bursztyn}

El artículo contiene una visión crítica sobre los procesos de restructuración del Estado basados en la lógica neoliberal, que caracterizan las reformas minimalistas de los 80 .

El tema de la reforma del Estado es visto como uno de los grandes desafios intelectuales y políticos de este fin de siglo, que debe, necesariamente, ser contextualizado históricamente, una vez que no existe una única crisis del Estado, mas varias crisis de los Estados, específicas y particulares, cuyas soluciones no son ni únicas ni universales, mas dependientes del diagnóstico de cada caso.

Se comprende que la razón desestatizante presenta limitaciones, reconocidas hasta aún por las instituciones financieras internacionales que anteriormente la defendían. El escenario de un nuevo modo de actualización estatal es presentado como lo más probable y el concepto de restatizaciones presentado como lo más adecuado para los cambios que se hacen necesarios.

\section{Introduction to the critique of the denationalising reasoning Marcel Bursztyn}

The paper covers a critical view of the State restructuring processes based on neoliberal logics, which characterised the minimalist reforms of the eighties.

The theme of State reform is seen as one of the great intellectual and political challenges of the end of the century and it should necessarily be historically contextualized, since there is not one single State crisis, but several State crises, specific and private, for which solutions are not unique or universal, but depend on the diagnosis for each case.

It is understood that the denationalising reasoning presents shortcomings, recognised even by the international financial institutions that once defended it. The scenery for a new way of state performance is presented as being most likely, the concept of renationalising being the most adequate for the changes that are needed.
Revista do

Serviço

Público

Ano 49

Número 1

Jan-Mar 1998

Doutor em desenvolvimento econômico e social e professor da Universidade de Brasília 



\section{Cartão de assinatura da RSP}

Para assinar a Revista do Serviço Público, preencha este cartão e envie ao endereço abaixo por fax ou correio.

Periodicidade: quadrimestral

Assinatura anual: $\mathrm{R} \$ 30,00$

Exemplar avulso de 1997: $\mathrm{R} \$ 12,00$

Exemplar avulso anterior a 1997: $\mathrm{R} \$ 8,00$

Nome/Instituição:

\section{CPF/CGC:}

Endereço:

\begin{tabular}{lcc}
\hline Cidade: & UF: & CEP: \\
\hline Telefone: & \multicolumn{2}{c}{ Fax: } \\
\hline
\end{tabular}

\section{Tipo de solicitação}

Assinatura

Número avulso - Edição $n^{-}$

Alteração de cadastro

\section{Forma de Pagamento}

Cheque nominal à ENAP - Fundação Escola Nacional de Administração Pública

Ordem de pagamento (anexar cópia do comprovante de depósito) em nome da ENAP Escola Nacional de Administração Pública, através do Banco do Brasil S/A, Agência Asa Sul 3478-9, Conta Corrente: 55.595.006-9

Nota de empenho em nome da ENAP Escola Nacional de Administração Pública (anexar original).

(UG:114702, Gestão: 11401)

Assinatura:

Data: /199

ENAP — Escola Nacional de Administração Pública

Diretoria de Pesquisa e Difusão

SAIS - Área 2-A

70610-900 - Brasília, DF

Tel: (061) 2457878 ramal 210 - Telefax: (061) 2456189

CGC: 00627 612/0001-09

http://www.enap.gov.br 



\title{
Publicações ENAP
}

\section{Conheça a Série Cadernos ENAP}

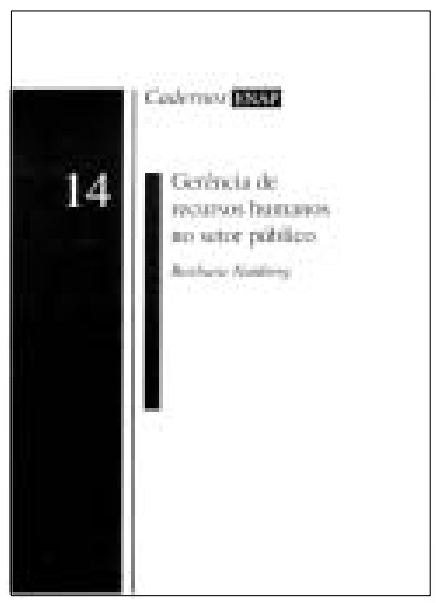

\author{
Nos Cadernos ENAP são publicados \\ relatórios atuais de pesquisa e \\ documentos de governos sobre temas \\ atuais relacionados ao Estado, à \\ administração pública e à gestão \\ governamental.
}

\section{Caderno ENAP no 14}

Documento elaborado por Barbara Nunberg - Especialista senior em administração pública, integrante da equipe do Setor de Administração Pública do Banco Mundial, do Departamento Técnico para Assuntos da Europa, Ásia Central, Oriente Médio e Norte da África - que examina as diversas práticas de gerenciamento de recursos humanos adotadas em alguns países industrializados, abordando temas como: planejamento de RH, recrutamento, formação de quadros de elite, classificação, remuneração e sistema de carreiras.

Conheça também outros temas, solicitando o Catálogo de Publicações.

\section{Para adquirir os Cadernos ENAP escolha uma das opções abaixo:}

1. Enviar cheque nominal em nome de: ENAP - Fundação Escola Nacional de Administração Pública.

2. Enviar ordem de pagamento (anexar cópia do depósito) em nome de: ENAP - Fundação Escola Nacional de Administração Pública, através do Banco do Brasil S/A - Agência: Asa Sul no 3478-9 — c/c no 55.595.006-9.

3. Enviar nota de empenho (anexar original) em nome de: ENAP — Fundação Escola Nacional de Administração Pública - UG: 114702 — Gestão: 11401

\section{Endereço para contato:}

SAIS - Área 2-A - 70610-900 - Brasília - DF

Telefax: (061) 2456189

http://www.enap.gov.br

e-mail:enap@mare.gov.br 